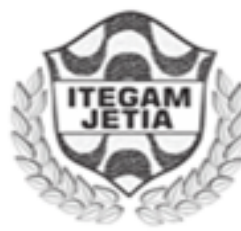

\title{
Science and Modernity: A Critical Needs
}

\author{
Dorli João Carlos Marques ${ }^{1}$, Iracelma Magalhães da Costa Marques $^{2}$ \\ ${ }^{I}$ Doutor em Biotecnologia pela Universidade Federal do Amazonas (UFAM). Professor do Mestrado em Segurança Pública, \\ Cidadania e Direitos Humanos da Universidade do Estado do Amazonas (UEA) e do Centro Universitário do Norte (UNINORTE). \\ E-mail: dorlimarques@yahoo.com.br. \\ ${ }^{2}$ Acadêmica de Direito do Centro Universitário do Norte (UNINORTE).E-mail: iracelmamarques@yahoo.com.br
}

\begin{abstract}
Modern science has no basis of positivist epistemological and methodological foundations sufficient for building a comprehensive understanding of the world of man and society. A study of contrasts to the paradigms of science, technology and modern rationality expressed the thoughts of Jürgen Habermas, Herbert Marcuse, Martin Heidegger, Theodor Adorno, Max Horkheimer, and Boaventura Santos Souza was conducted. We used a dialectic approach to highlight the contradictions and limitations of this paradigm and highlight other paradigms of positivist epistemological basis not carry that enabled the overcoming of knowledge as regulation by knowledge empowerment. It was evident, based on the theories of these authors and arguments of researchers such as Albert Einstein, Ilya Prigogine, Michel Foucault, among others, that modern science has methodological limitations Cartesian basis and fragile epistemological basis when trying to conceive man, world and society while dynamically articulated.
\end{abstract}

Keywords: science; modernity; epistemological crisis.

\section{RESUMO}

\section{Ciência e Modernidade: Uma Crítica Necessária}

A ciência moderna de base positivista não apresenta fundamentos epistemológicos e metodológicos suficientes para a construção de uma compreensão ampla do mundo, do homem e da sociedade. Foi realizado um estudo das contraposições aos paradigmas da ciência, técnica e racionalidade modernas, expressas nos pensamentos de Jürgen Habermas, Herbert Marcuse, Martin Heidegger, Theodor Adorno, Max Horkheimer, e Boaventura Souza Santos. Utilizou-se uma abordagem dialética para evidenciar as limitações e contradições desse paradigma e destacar outros paradigmas de base epistemológica não positivista que possibilitassem proceder a superação do conhecimento enquanto regulação pelo conhecimento emancipação. Evidenciou-se, com base nas teses dos autores supracitados e de argumentos de pesquisadores como Albert Einstein, Ilya Prigogine, Michel Foucault, entre outros, que a ciência moderna de base cartesiana apresenta limitações metodológicas e base epistemológica frágil quando se busca conceber homem, mundo e sociedade enquanto dinamicamente articulados.

Palavras-chave: ciência; modernidade; crise epistemológica.

\section{INTRODUÇÃO}

O trabalho com o conhecimento possui uma complexidade muitas vezes negligenciada. Conhecer é antes de tudo interagir com o mundo e com o outro. Nessa tarefa, vamos construindo sentidos e nos fazendo sujeitos num processo permanente de autoconstrução, permeado tanto pelos conflitos próprios das interações quanto pelo enfrentamento das verdades científicas cristalizadas pelos longos períodos de seu manuseio irrefletido. Portanto, esses processos não ocorrem passivamente.

Entende-se que esse enfrentamento passa por dois momentos: a elaboração de uma revisão dos marcos teóricoconceituais da ciência moderna e uma avaliação dos paradigmas emergentes, notadamente aqueles que levem em consideração a complexidade do mundo real. $\mathrm{O}$ objetivo principal do artigo é contribuir para a ampliação das condições de emergência de uma nova epistemologia que supere, dentre outras, a visão dicotômica de ciência que separa em universos distintos homem 
e natureza e que banaliza e/ou confunde conceitos básicos no campo epistemológico.

Entende-se que esta discussão se faz necessária em todos os contextos onde tais questões se apresentem, porém no contexto amazônico, além de necessária ela é urgente. $\mathrm{Na}$ Amazônia é superlativo tanto a diversidade natural quanto a pluralidade sociocultural, além da fragilidade e os riscos a que os integrantes da sociobiodiversidade estão expostos.

A matriz epistemológica justificadora da lógica socioeconômica, política e cultural que tem sido posta em prática na região, tanto por setores da iniciativa privada quanto parte do setor público não deixa dúvidas quanto aos riscos que a vida, em sentido lato está submetida. Exemplos dessa lógica podem ser constatados a partir dos estudos de impactos socioambientais nas áreas onde se instalaram os megaprojetos agropecuários, de mineração, de geração de energia etc, que têm sido implementados na região e amplamente estudados por pesquisadores, como [1][2][3][4], entre outros.

\section{GÊNESE E TRAJETÓRIA DA CRÍTICA À CIÊNCIA E À MODERNIDADE}

Falar em crítica da ciência e da modernidade é remeterse, necessariamente, à Escola de Frankfurt, importante centro de estudos sobre a pós-modernidade e da crítica às teorias experimentais e empíricas hegemônicas. Essa Escola teve como principais participantes, em um primeiro momento, Max Horckheimer [1895 - 1973], Theodore Adorno [1903 - 1969] e Herbert Marcuse [1898 - 1979], Walter Benjamin [1892 - 1940] e Siegfried Kracauer [1889 -1966]. Eles postularam uma teoria crítica imbricada no processo de mudança histórica, tanto no que se refere a perspectivas analíticas ao presente, quanto uma consciência de futuro.

Em tese publicada em 1947 sob o título de Dialética do Esclarecimento, Theodor Adorno e Max Hockheimer, desenvolvem o conceito de "indústria cultural", denunciando as artimanhas de grupos conservadores, cuja intenção era a de impedir a formação de indivíduos autônomos, independentes, capazes de julgar e de decidir conscientemente.

Posteriormente, essa tese foi retomada por Herbert Marcuse acrescentando, em tom de denúncia, um dos eixos de legitimação dessa lógica: a indústria cultural leva a uma massificação cultural através da qual os indivíduos são induzidos a crer numa ideia comum e não em ideias diversificadas. A cultura torna-se uma indústria não só por ser organizada ao longo das linhas de produção e distribuição de massas; ela também torna os produtos numa extensão da lógica do trabalho, controlando formas válidas de diversão e integrando-as no ciclo de produção e de consumo.

No mesmo diapasão Jürgen Habernas, traz à baila a noção de racionalidade proposta por Max Weber. Para Habermas, aquilo que Max Weber chamou de "racionalização" contraditoriamente não insere a ideia de racionalidade e em seu nome está o interesse de dominação política oculta. Por isso, propõe que o conceito de racionalidade de Weber seja reestruturado, já que "Max Weber introduziu o conceito de racionalidade para definir forma de atividade econômica capitalista, do tráfego social regido pelo direito privado burguês e da dominação burocrática" [5].

Na proposta de Weber, a progressiva racionalização da sociedade depende da institucionalização do progresso técnico e cientifico. A técnica e a ciência ao progredirem invadem as esferas institucionais da sociedade, modificando as próprias instituições. O processo de secularização e o enfraquecimento das cosmovisões seriam reflexos da crescente racionalidade da ação social.

Ressalte-se, conforme explicitado anteriormente, que aquilo a que Weber chamou de racionalização, não se refere à racionalidade como tal, mas uma forma determinada de dominação política velada por diversos mecanismos de dominação. Nesse sentido, é pedagógico o conceito de razão técnica e sua inter-relação com o conceito de ideologia apresentado por [5]:

Não só na sua aplicação, mas já a própria técnica é dominação metódica, científica, calculada e calculante (sobre a natureza e sobre o homem). Determinados fins e interesses da dominação não são outorgados à técnica apenas 'posteriormente' e a partir de fora - inserem-se já na própria construção do aparelho técnico; a técnica é, em cada caso, um projeto históricosocial; nele se projeta o que uma sociedade e os interesses nela dominantes pensam fazer com os homens e com as coisas.

De acordo com o autor em questão, nas sociedades capitalistas hegemônicas a dominação tende a abandonar seu caráter explicitamente explorador e opressor e disfarçar-se de racional, numa clara estratégia de dominação política. Tal estratégia se concretiza através de práticas como a repressão, a sujeição dos indivíduos à lógica de produção e distribuição dos bens, a desprivatização do tempo livre e a fusão do trabalho social produtivo e destrutivo. Para que essa repressão do espírito humano possa perdurar por um tempo maior, a indústria cultural entra em cena com todo o seu aparato ideológico numa tentativa 
de fazer desaparecer das consciências dos indivíduos a sensação de repressão por conta de uma nova forma de legitimação: a ilusão de que o aumento da produtividade e do domínio sobre a natureza vem acompanhado de níveis mais confortáveis de vida para todos os indivíduos.

Deve-se atentar também para o aspecto apologético dessa dúbia racionalidade onde as forças de produção podem se justificar como "um enquadramento institucional funcionalmente necessário" [5]. À medida que a racionalidade tem sua eficiência apologética aumentada, reduz-se o seu papel de instrumento de crítica, rebaixando-a a mero corretivo dentro do sistema.

Até mesmo o instrumental metodológico da ciência tem um papel a desempenhar nessa lógica de dominação: "O método científico, que levava sempre a uma dominação cada vez mais eficaz da natureza, proporcionou depois também os conceitos pretensamente puros e os instrumentos para uma dominação cada vez mais eficiente do homem sobre os homens, através da dominação da natureza" [5]. Mais do que isso, o autor em questão destaca que, a dominação perpetua-se não somente "mediante a tecnologia", mas "como tecnologia". A tecnologia fornece legitimação ao poder político, que passa a controlar todas as esferas da cultura.

$\mathrm{O}$ autor em tela completa o raciocínio ressaltando a importância de atentar para transformação do conteúdo político da razão técnica em ponto de partida analítico para compreender a sociedade tardo-capitalista afirmando que "não se pode pensar numa emancipação sem antes revolucionar a própria ciência e técnica" [5].

Uma das possibilidades de transformação profunda da ciência e da técnica é o reencontro da ciência e da técnica com a ética. A ciência e a técnica englobariam conhecer a vida, o homem, a natureza, o universo num exercício reflexivo sobre o sentido da ciência e da técnica no mundo, já que ambas são atividades humanas e não há como conhecer sem valorar, isto é, o valorar é parte intrínseca do conhecer.

Nesse contexto, outras formas de conhecimento, notadamente os conhecimentos das populações tradicionais, não podem ser desconsideradas pela ciência e pela técnica ditas modernas, pois possuem elevado valor simbólico para as populações tradicionais, dando sentido especial às suas existências. A fauna, a flora, a terra, as formas do relevo, os astros, os rios, igarapés, lagos e tudo o mais que os rodeia são carregados de simbolismo.
No diapasão de Habermas, Herbert Marcuse segue questionando o conceito de ciência, apesar de não chegar a deduzir a ideia de uma nova técnica. Ele propõe outra atitude perante a natureza: ao invés de se tratá-la como objeto de uma disposição possível, propõe considerá-la como a interlocutora de uma possível interação. Em vez da natureza explorada, pode-se buscar a "natureza fraternal" [6].

A defesa do fim das imposições presente no pensamento de ambos remete à ideia de autonomia, um dos princípios teleológicos básicos presentes nos estudos da ética em geral e da bioética em particular. A esse respeito, [6] assevera que a técnica e a ciência cumprem ainda hoje uma função legitimadora da dominação, acrescentando que a regulação do processo econômico pela intervenção do Estado surgiu muito mais em razão de controlar as disfunções que ameaçavam o sistema capitalista quando abandonado a si mesmo do que efetivamente reduzir as desigualdades socioeconômicas. $\mathrm{O}$ autor ainda salienta que a evolução do capitalismo também estava em contradição com a ideia de uma sociedade civil que se emancipa da dominação e neutraliza o poder.

Também é merecedora de uma apreciação crítica mais detalhada a ideia de troca - justificadora do capitalismo. Ensina [4] que a troca processada nesses moldes, surge da necessidade de uma nova legitimação. Contudo, essa legitimação já não pode deduzir-se de uma ordem apolítica, isto é, das relações de produção.

Dessa forma, a ideologia capitalista é substituída por um programa substitutivo que se orienta pelas consequências sociais, não da instituição do mercado, mas de uma atividade estatal que compensa as disfunções do intercâmbio livre. Esse programa une a ideologia burguesa do rendimento à garantia de um mínimo de bem-estar, da estabilidade no trabalho e nos rendimentos.

Nesse contexto, a política assumiria um papel não dignificante, de mera prevenção das disfuncionalidades do sistema. Como resultado, a atividade estatal passaria a se restringir a tarefas técnicas resolúveis administrativamente, abandonando as questões mais complexas. Como consequência, ter-se-á um processo sempre crescente de despolitização do conjunto dos atores sociais, uma vez que se excluem as questões práticas e a discussão pública dos critérios técnicos.

Quando as decisões acontecem a partir de uma imposição, onde as bases não têm participação efetiva, a técnica e a ciência, aqui entendida como uma consciência positivista imperante e articulada como consciência tecnocrática, passam a assumir a posição de uma ideologia que às vezes substitui as 
ideologias burguesas decadentes fazendo-as ressurgir com outra feição, não raro buscando justificá-las. Essa lógica, porém, quando tem sua trajetória analisada atentamente, expressa o que [6] classificou como irracionalidade da sociedade capitalista.

Para este autor, a irracionalidade da sociedade moderna reside no fato de ser produto de uma vontade particular, o capitalismo, e não de uma vontade geral e autoconsciente. Essa visão, apesar de apresentar traços do romantismo do século XVIII e do socialismo utópico do século XIX, traz em seu bojo evidente influência do marxismo, na medida em que evidencia a contradição fundamental e totalizante entre o caráter social da produção e o caráter privado da apropriação, que conduz a um antagonismo irredutível entre as duas classes principais da sociedade capitalista: a detentora do capital e da "moderna" tecnologia e os empobrecidos por esse mesmo sistema. Nesse sentido, observa-se que a crítica esboçada pelo autor supracitado, tende a conceber a sociedade como uma totalidade, requerendo uma alternativa igualmente totalizante à sociedade existente.

A apreensão desse cenário, a partir das perspectivas propostas por Habermas, Marcuse, Hockheimer e outros, evidencia a necessidade de apresentar e/ou construir alternativas que superem esse modelo. Entende-se que alguns caminhos já foram percorridos nesse sentido; entretanto, há muito por caminhar.

\section{Alguns caminhos possíveis para a superação da ciência e da racionalidade modernas}

A construção caminhos alternativos aos da ciência, da técnica e da racionalidade moderas requer zelo epistêmico. As concepções totalizantes - na medida em que buscam abarcar o todo social em um princípio único de transformação social, um conjunto dos agentes coletivos e o complexo de relações de poder presentes no conjunto de ralações sociais - se não oportunizar ao conjunto dos atores procederem ao que [8] chama de "emancipação social", corre-se o risco de incorrer-se na armadilha da "regulação social", própria das visões funcionalistas da sociedade e das concepções epistêmicas próprias ao cientificismo moderno que se busca superar.

A esse respeito, [8], outro importante crítico da ciência dita moderna, afirma que não há saída emancipatória possível dentro do regime da verdade imposto pela ciência moderna, já que a resistência transforma, ela própria, num poder disciplinar e, portanto, numa opressão consentida e interiorizada. $\mathrm{O}$ autor em tela mostra, de maneira cristalina, as opacidades e os silêncios produzidos pela ciência moderna, postulando ser necessário a busca de regimes de verdade alternativos, outras formas de conhecer até então marginalizadas, suprimidas e desacreditadas pela ciência moderna.

No diapasão de [8] [9] assevera que "o nosso lugar é hoje um lugar multicultural, um lugar que exerce uma constante hermenêutica de suspeição contra supostos universalismos ou totalidades". Essa visão de mundo, de homem e de sociedade entende que não há um princípio único de transformação social e sim variadas possibilidades de princípios e futuros; não há sujeitos históricos únicos nem uma forma única de dominação. São múltiplas as faces da dominação e da opressão o que requer, obviamente, múltiplas formas de enfrentamento das mesmas.

Uma das possibilidades desse enfrentamento é, na concepção de [8], proceder à construção de uma crítica pósmoderna ao conhecimento-regulação que a modernidade eurocêntrica impôs ao conjunto da sociedade. Tal enfrentamento deve se iniciar pela crítica do conhecimento. $\mathrm{Na}$ atual fase de transição paradigmática a teoria crítica pós-moderna constrói-se a partir de uma tradição epistemológica marginalizada e desacreditada da modernidade: o conhecimento-emancipação. Nesta forma de conhecimento a ignorância é o colonialismo e o colonialismo é a concepção do outro como objeto e, consequentemente, o não reconhecimento do outro como sujeito. Ademais, conforme assevera Heidegger (2006), a ciência não um ente em si, mas um para nós, aqui entendido como voltada para o conjunto da sociedade.

A construção dessa nova concepção de ciência, técnica e a racionalidade a elas subjacente passa pelo pressuposto de que o conhecimento é sempre contextualizado pelas condições que o tornam possível e de que ele só progride na medida em que transforma, em sentido progressista, essas condições. Por isso o conhecimento-emancipação é conquistado na medida em que se assume as consequências do seu impacto. Outro pressuposto importante presente na construção dessa crítica, nos moldes propostos pelo autor em questão, diz respeito à dicotomia consenso-resignação. Socorrendo-se de Marx e Gramsci, [6] afirma que a teoria crítica sempre entendeu por hegemonia a capacidade das classes dominantes em transformarem as suas ideias de modo a fazer crer os incautos serem verdadeiras as suas teses. Questionar os paradigmas sobre os quais se assentam tais teses é conditio sine qua non para o atendimento de uma nova concepção de ciência.

O autor supracitado afirma que o modelo de racionalidade sobre o qual a ciência moderna se assenta, constituiu-se a partir da revolução científica do século XVI e foi desenvolvida nos séculos seguintes basicamente no domínio das ciências naturais. A partir de então se pôde falar de um modelo 
global, isto é, ocidental de racionalidade científica que admite variedade interna, mas que se defende ostensivamente das formas de conhecimento por eles identificada como não científico: o senso comum, o conhecimento tradicional - notadamente o indígena e todo um leque de conhecimentos que precisam hodiernamente ser identificados como humanidades, que têm como uma de suas características epistemológicas básicas a necessária construção dos seus objetos de conhecimentos, já que os mesmos não nos são dados a priori. [8] ao mesmo tempo que descreve, também adverte sobre o modelo de racionalidade científica cartesiano:

Sendo um modelo global, a nova racionalidade científica é também um modelo totalitário, na medida em que nega o caráter racional a todas as formas de conhecimento que se não pautarem pelos seus princípios epistemológicos e pelas suas regras metodológicas. É esta a sua característica fundamental e a que melhor simboliza a ruptura do novo paradigma científico com os que o precedem. Está consubstanciada, com crescente definição, na teoria heliocêntrica do movimento dos planetas de Copérnico, nas leis de Kepler sobre as órbitas dos planetas, nas leis de Galileu sobre a queda dos corpos, na grande síntese da ordem cósmica de Newton e, finalmente, na consciência filosófica que lhe conferem Bacon e Descartes.

Ora, não se pode falar em rigor científico quando os dados são aferidos tão somente pelo rigor das medições. As qualidades intrínsecas do real são, por assim dizer, desqualificadas e em seu lugar passam a imperar as quantidades em que eventualmente se podem traduzir. $O$ que não é quantificável é cientificamente irrelevante. Os conhecimentos que não se enquadrem nesse rigorismo cartesiano e tudo o que o envolve e permeia, mormente no que tange ao seu rico universo simbólico passam a ser adjetivados de exótico, expressando mais que o diferente: $\mathrm{o}$ inútil.

Observa-se ainda que essa concepção de método científico assenta-se na redução da complexidade que caracteriza a realidade. Conhecer é dividir e classificar para depois poder determinar relações sistemáticas entre o que se separou. "Dividir cada uma das dificuldades [...] em tantas partes quanto for possível e requerido para melhor as resolver" [10]. Esse conhecimento é marcadamente causal que aspira à formulação de leis, à luz das regularidades observadas, com vistas a prever o comportamento futuro dos fenômenos.

A elaboração de tais leis se processa, por um lado, através do isolamento das condições iniciais consideradas relevantes e, por outro lado, no pressuposto de que o resultado se produzirá independentemente do lugar e do tempo em que se realizarem as condições iniciais. Nesse sentido, tais leis representam uma redução do conceito de causalidade proposto por Aristóteles que distinguia quatro tipos de causa: a causa material, a causa formal, a causa eficiente e a causa final. As leis da ciência moderna, na medida em que privilegia precipuamente o funcionamento do objeto do conhecimento em questão em detrimento da discussão sobre qual agente e qual o fim das coisas, reduz de forma deliberada a intencionalidade do sujeito autor da ação cognitiva.

Um conhecimento baseado na formulação de leis tem como pressuposto metateórico a ideia de ordem e de estabilidade do mundo, a ideia de que o passado se repete no futuro. Segundo a mecânica newtoniana, o mundo da matéria é uma máquina cujas operações se podem determinar exatamente por meio de leis físicas e matemáticas, um mundo estático e eterno a flutuar no espaço vazio, um mundo que o racionalismo cartesiano torna cognoscível por via da sua decomposição nos elementos que o constituem. Esta ideia do mundo máquina é de tal modo poderosa que vai transformar-se em grande hipótese universal da época moderna. [...] Este vai ser o grande sinal intelectual da burguesia. O determinismo mecanicista é o horizonte certo de uma forma de conhecimento que se pretende utilitário e funcional, reconhecido menos pela capacidade de compreender profundamente o real do que pela capacidade de o dominar e transformar [6].

Esse modelo de racionalidade científica apresenta evidentes sinais de crise do paradigma epistemológico moderno. As bases sobre as quais esse paradigma se assenta já não são suficientes para explicar a realidade em profundidade. Sua fragilidade foi demonstrada por Einstein [1879-1955] quando distinguiu a simultaneidade dos acontecimentos presentes no mesmo espaço e a simultaneidade dos acontecimentos distantes, em particular de acontecimentos separados por distâncias astronômicas. Em relação a esses últimos, Einstein identificou um problema de ordem lógica expresso na impossibilidade de se determinar a simultaneidade dos acontecimentos nos espaços presente e distante. Dessa forma, não havendo simultaneidade universal, o tempo e o espaço absolutos de Newton deixam de existir. Dois acontecimentos simultâneos num sistema de referência não são simultâneos noutro sistema de referência.

A fragilidade da visão da física clássica newtoniana inspirou Einstein a relativizar o rigor das leis da física nos domínios da astrofísica e a propor a mecânica quântica no domínio da microfísica. Segundo [6] "Heisenberg e Bohr demonstraram que não é possível observar ou medir um objeto sem interferir nele, sem o alterar, e a tal ponto que o objeto que 
sai dessa medição não é o mesmo que lá entrou [...]". O autor em questão assevera, baseado no princípio da incerteza $[11]^{1}$, que não conhecemos do real senão o que nele introduzimos, ou seja, que não conhecemos do real senão a nossa intervenção nele. Mesmo o rigor matemático quando posto a serviço de medições na física quântica se revela insuficiente, nos casos em que se formularem proposições que não puderem ser refutadas nem demonstradas como, por exemplo, nos casos de postulados de caráter não contraditório.

Esta concepção epistemológica encontra eco em pensadores da ciência do quilate do físico-químico russo Ilya Prigogine [1917-2003], para quem a teoria das estruturas dissipativas e o princípio da ordem se estabelecem através das flutuações em sistemas abertos ${ }^{2}$. Essas flutuações de energia podem produzir um novo estado, representado pela potencialidade do sistema em ser atraído para um novo estado de menor entropia, de modo que a irreversibilidade nos sistemas abertos significa que eles são produto da sua história [6]. Essa teoria não é fenômeno isolado. Faz parte de um movimento convergente atual que atravessa vários campos da ciência, num movimento transdisciplinar que Jantsch designa por paradigma da auto-regulação e que se ramifica por outras teorias tais como no conceito de Hiperciclo e na teoria da origem da vida de Eigen e P. Schuster e no conceito de Autopoiesis de Maturana e Varela.

\section{Considerações Finais}

Os processos de reflexão são fundantes de toda possibilidade de conhecimento, especialmente porque não bastam informações para nos fazer saber das coisas; é preciso reorganizá-las, reformulá-las, analisá-las e reagrupá-las para que se possa ter acesso às múltiplas leituras dos seus sentidos e dos seus significados.

Foi a partir desta compreensão e de como se processa a apreensão do real e a produção do conhecimento, que nos propusemos questionar os conceitos de ciência, técnica e

$[12]^{1}$ Segundo esse princípio, não se podem reduzir simultaneamente os erros de medição da velocidade e da posição das partículas; o que for feito para reduzir o erro de uma das medições aumenta o erro da outra - [Tradução livre] (HEISENBERG, Werner. Physics and Beyond. Londres: Allen \& Unwin, 1971).

\footnotetext{
${ }^{2}$ Essa teoria afirma que em sistemas que funcionam nas margens da estabilidade, a evolução se explica por flutuações de energia que em determinados momentos, nunca inteiramente previsíveis, desencadeiam espontaneamente reações que, por via de mecanismos não lineares, pressionam o sistema para além de um limite máximo de estabilidade e o conduzem a um novo estado macroscópico. Esta transformação irreversível e termodinâmica é o resultado da interação de processos microscópicos segundo uma lógica de auto-organização numa situação de não-equilíbrio [8].
}

racionalidade modernas e a propor caminhos que pudessem alargar esses conceitos, por entendermos que, da forma como foram inicialmente propostos, não atendiam às visões de homem, de mundo e de sociedade que a ciência e a ética requerem nos dias atuais.

$\mathrm{Na}$ primeira parte do texto foram expostos os questionamentos às visões e práticas da ciência e da racionalidade modernas é fundamental. Reconhece-se a importância de ambas por ocasião da superação da visão de homem, de mundo e de sociedade que imperou em partes da Europa Ocidental no período medieval. Entretanto, atualmente, conforme exposto ao longo do texto, essas visões e as práticas delas decorrentes não atendem mais ao que os tempos atuais impõem a todos os que fazem ciência.

$\mathrm{Na}$ segunda parte do texto, demonstrou-se que a construção dessa nova epistemologia encontra eco nos pensamentos de autores como Jürgen Habermas, Herbert Marcuse, Martin Heidegger, Theodor Adorno, Max Horkheimer, e Boaventura Souza Santos, entre outros. O objeto da ciência não é mais simplesmente um ente em si, mas um para nós. A exclusão do conjunto dos atores sociais dos processos de discussão, decisão e repartição dos benefícios decorrentes dos processos produtivos é contrário infringe o estabelecido tanto nos aspectos deontológicos quanto teleológicos da ética. Ética.

Por fim, quer-se enfatizar que a dicotomia entre ciência e axiologia não faz mais sentido, pois ciência é ação construtiva e/ou produtiva e toda ação envolve valores, os quais repercutem sobre os seres humanos, na medida em que produz resultados que interferem sobre o mundo, a vida, a natureza e o homem.

\section{Referências Bibliográficas}

[1] KOHLHEPP, Gerd. Conflitos de interesse no ordenamento territorial da Amazônia brasileira. Estudos Avançados. vol. 16, no. 45. São Paulo: mai/ago 2002.

[2] CASTRO, Edna. Expansão da fronteira, megaprojetos de infraestrutura e integração sul-americana. Caderno CRH. v. 25, n. 64, p. 45-61. Salvador: jan./abr. 2012.

[3] WITKOSKI, Antonio Carlos. Terras, florestas e águas de trabalho: os camponeses amazônicos e as formas de usos dos seus recursos naturais. 2. ed. São Paulo: Annablume, 2010. v. 1. $484 \mathrm{p}$.

[4] RODRIGUES, Renan Albuquerque. Vidas despedaçadas: impactos socioambientais da construção da usina hidrelétrica de Balbina (AM), Amazônia Central. 2013. 369 f. Tese (Doutorado em Sociedade e Cultura na Amazônia) - Curso de Pós-Graduação 
em Sociedade e Cultura na Amazônia, Universidade Federal do Amazonas, Manaus.

[5] HABBERMAS, Jürgen. Técnica e Ciência como ideologia. Lisboa/Portugal: Edições 70, 2009. 147 p.

[6] MARCUSE, Herbert. Razão e Revolução: Hegel e o advento da teoria social. São Paulo: Paz e Terra, 2005. 380p.

[7] HORKHEIMER, Max. Eclipse da razão. Rio de Janeiro: Editorial Labor do Brasil, 1972. 192 p.

[8] SANTOS, Boaventura de Sousa. Um discurso sobre as ciências. 7. ed. São Paulo: Cortez, 2010. 92 p.

[9] FOUCAUlT, Michel. Vigiar e Punir. 35. ed. Petrópolis: Vozes, 2008. 262 p.

[10] DESCARTES, René. Discurso sobre o método. Coleção Textos Filosóficos. Petrópolis-RJ: Vozes, 2008. 72p.

[11] HEISENBERG, Werner. Physics and Beyond. Londres: Allen \& Unwin, 1971). 